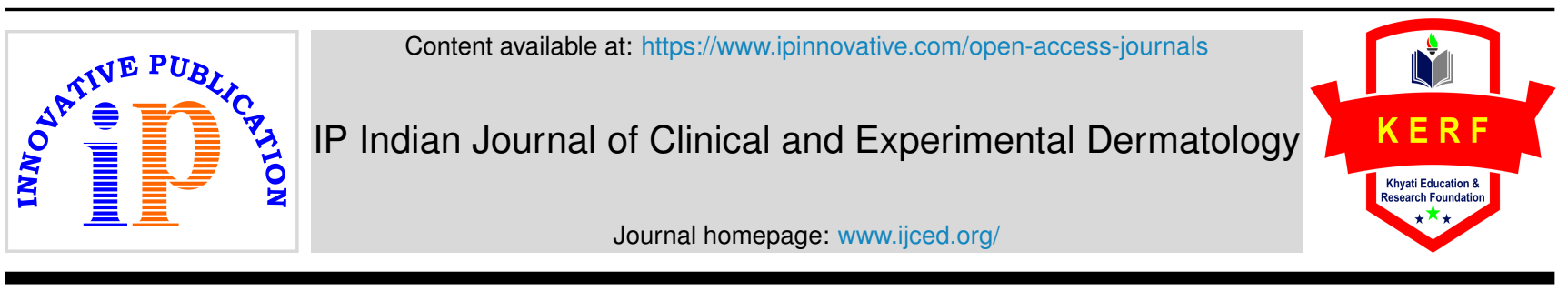

Original Research Article

\title{
Study of efficacy and cost effectiveness of topical permethrin, benzyl benzoate and oral ivermectin in the treatment of scabies
}

\author{
Rashmi R Mallya ${ }^{1, *}$, Ranga Swaroop ${ }^{1}$, K Yashwanth Reddy ${ }^{1}$, Avik Ghosh ${ }^{1}$, \\ Zigu S Krishn" \\ ${ }^{1}$ Dept. of Dermatology, Adichunchanagiri Health and Research Centre, Mandya, Karnataka, India
}

\section{A R T I C L E I N F O}

\section{Article history:}

Received 29-10-2020

Accepted 25-12-2020

Available online 22-02-2021

\section{Keywords:}

Scabies

Permethrin

Ivermectin

Benzyl benzoate

Pruritus.

\begin{abstract}
A B S T R A C T
Background: Scabies is an ectoparasitic infestation caused by the mite Sarcoptes scabiei var hominis that occurs due to direct skin to skin contact.It is a common public health problem that affects humans regardless of age, gender and social class. An ideal scabicide should be effective against both adult and egg of the mite, easily applicable, acceptable, nontoxic, and economical. It should be safe to use in all ages.

Objectives: To compare the therapeutic efficacy and cost effectiveness of topical 5\% permethrin, $25 \%$ benzyl benzoate and oral ivermectin $(200 \mathrm{mcg} / \mathrm{kg} / \mathrm{dose})$ in the treatment of scabies.

Materials and Methods: A total of 90 patients with scabies attending the dermatology outpatient at the Department Of Dermatology, Venereology and Leprosy, Adichunchanagiri Hospital and Research Centre, B.G. Nagara, were randomly divided into three treatment groups A, B and C with 30 patients in each group. Group A patients received 5\% permethrin cream which was made to remain in contact with the skin for at least 8 hours. This was repeated after 7 days. Group B patients received $25 \%$ benzyl benzoate lotion which was made to remain in contact with the skin for at least 8 hours. This was done for three consecutive nights. Group C patients received oral ivermectin in a single dose of $200 \mathrm{mcg} / \mathrm{kg}$ body weight taken with meals and it was repeated after 10 days. All patients were followed up at the end of first, second and third week to assess clinical grading score and pruritus grading score by visual analogue scale. The cost effectiveness was calculated on basis of total expenditure on medicine at the end of the third week and cure rate of the three groups were compared on the basis of amount needed to treat one case successfully.

Results: At the end of third week, complete clinical cure was seen in 28 (93.3\%) patients in group A, 13 $(43.3 \%)$ patients in group B and $22(73.3 \%)$ of patients in group C. Permethrin was more efficacious than benzyl benzoate and ivermectin, which was found to be statistically significant ( $\mathrm{p}$ value $=0.00003,0.037$ respectively).

At the end of treatment, benzyl benzoate was more cost effective than permethrin ( $\mathrm{p}$ value $<0.00001)$ and ivermectin. This was found to be statistically significant.

Conclusion: From this study it can be concluded that topical permethrin is the most efficacious in the treatment of scabies, compared to oral ivermectin and topical benzyl benzoate.

However, topical benzyl benzoate was most cost effective than topical permethrin and oral ivermectin.
\end{abstract}

(C) This is an open access article distributed under the terms of the Creative Commons Attribution License (https://creativecommons.org/licenses/by/4.0/) which permits unrestricted use, distribution, and reproduction in any medium, provided the original author and source are credited.

\section{Introduction}

Scabies is an ectoparasitic infestation caused by the mite Sarcoptes scabiei var hominis that occurs due to direct skin to skin contact. ${ }^{1}$ It is a common public health problem

\footnotetext{
* Corresponding author.

E-mail address: rashmirmallya@gmail.com (R. R. Mallya).
}

that affects humans regardless of age, gender and social class.However, the main risk factors include poverty, poor hygiene, poor nutritional status and overcrowding, most of which are common problems found in rural areas. ${ }^{2}$

The number of infested cases worldwide is estimated to be up to 300 million. ${ }^{3}$ WHO has declared scabies to be a neglected disease of tropical areas. ${ }^{4}$ The burden of this 
disease is highest in developing countries where the disease is endemic.

Management of scabies includes use of topical antiscabietic drugs like permethrin $5 \%$ cream, benzyl benzoate $10-25 \%$ lotion, gamma benzene hexachloride $1 \%$ lotion, crotamiton $10 \%$ lotion, malathion $0.5 \%$ lotion applied all over the body for a specified contact period to patients and their close contacts and oral ivermectin in the dose of $200 \mathrm{mcg} / \mathrm{kg}$ body weight. ${ }^{1}$

An ideal scabicide should be effective against both adult and egg of the mite, easily applicable, acceptable, nontoxic, and economical. It should be safe to use in all ages. There are various treatment modalities for scabies but yet there is a lacuna for an ideal scabicide. ${ }^{1}$

The economical and psycho-social impact of this commonly prevalent disease is significant especially among the population who have poor affordability for the most efficacious anti-scabietic drug, hence carried out the present study to compare the therapeutic efficacy and cost effectiveness of topical $5 \%$ permethrin, benzyl benzoate $25 \%$ and oral ivermectin in patients with scabies at a rural tertiary care hospital.

\subsection{Objectives of the study}

1. To compare the therapeutic efficacy of topical $5 \%$ permethrin, $25 \%$ benzyl benzoate and oral ivermectin $(200 \mathrm{mcg} / \mathrm{kg} / \mathrm{dose})$ in the treatment of scabies.

2. To compare the cost effectiveness of topical $5 \%$ permethrin, $25 \%$ benzyl benzoate and oral ivermectin in the treatment of scabies.

\section{Materials and Methods}

\subsection{Source of data}

The study was conducted at the Department Of Dermatology, Venereology and Leprosy, Adichunchanagiri Hospital and Research Centre, B.G. Nagara, Nagamangala Taluk, Mandya District, on an outpatient basis.

\subsection{Study duration}

18 Months.

\subsection{Study subjects}

New patients of scabies diagnosed by dermatologist of either gender aged between 5 and 60 .

\subsection{Study design}

Quasi experimental study.

\subsection{Sample size}

Patientse in each group Total of 90 patients.

\subsection{Statistical analysis}

\subsubsection{Statistical software}

The Statistical software namely SPSS 22.0, and R environment ver.3.2.2 were used for the analysis of the data and Microsoft Word and Excel were used to generate graphs, tables etc.

Chi-square/ Fisher exact test was used to find the significance of study parameters on categorical scale between two or more groups, Non-parametric setting for Qualitative data analysis. Fisher exact test was used when cell samples were very small.

\section{Method of collection of data}

\subsection{Inclusion criteria}

1. New patients of scabies diagnosed by dermatologist of either gender aged between 5 and 60 .

2. Patients above 18 years of age willing to give consent to participate in the study.

3. Patients between 5 years and 18 years with guardian consent

\subsection{Exclusion criteria}

1. Patients with age less than 5 years and more than 60 years.

2. Patients having scabies with atypical presentations like crusted scabies, scabies incognito.

3. History of allergy to any of the study drugs.

4. Patients who had taken any anti-scabietic treatment in the past four weeks.

5. Patients with associated comorbid conditions like hypertension, diabetes mellitus, liver and kidney disorder.

\subsection{Procedure of the study}

A total of 90 patients with scabies attending the dermatology outpatient department and satisfying the aforementioned inclusion and exclusion criteria were recruited in the study. A detailed dermatological examination of the lesions along with baseline itching and clinical grade scoring was done.

\subsection{Diagnosis of scabies}

For the diagnosis of scabies, the following criteria was taken into consideration: ${ }^{5}$

1. History of intense nocturnal pruritus.

2. History of similar complaints in the close family members or contacts.

3. Patient presenting with typical lesions of scabies like burrows, vesicles, papules, nodules or pustules at classical sites on the body like interdigital folds of the hands, the flexor aspects of the wrists, elbows, the 
anterior and posterior axillary folds, the periumbilical areas, waist, shaft of penis, vulva, gluteal region and the lateral aspects of the feet. 6

4. Microscopic demonstration of the mite, egg, fecal pellets or larvae using $10 \%$ potassium hydroxide.

\subsection{Clinical grading of scabies}

At baseline, the severity of the lesions was clinically graded objectively on a scale of 0 to $3 .^{1}$

- Grade 0- free of lesions (no lesions)

- Grade 1- 10 or fewer lesions (mild)

- Grade 2- 11 to 49 lesions (moderate)

- Grade 3- 50 or more lesions (severe)

\subsection{Grading of pruritus}

The assessment of pruritus was done subjectively on a scale of 0 to 10 using visual analogue scale (VAS) at baseline.

Itching was graded on a visual analogue scale of 0 to 3 on basis of severity.

Patients were asked to score the pruritus from a range of 0 to 10 . Score 0 is considered as no itching while 10 is considered as worst or severe itching and was graded as follows: ${ }^{1}$

- Grade 0- no itching

- Grade 1- mild itching (score: 1-3)

- Grade 2- moderate itching (score: 4-6)

- Grade 3- severe or intense itching (score: 7-10).

\subsection{Sampling}

90 patients diagnosed with scabies was randomly divided into three treatment groups $\mathrm{A}, \mathrm{B}$ and $\mathrm{C}$ according to computer generated random numbers and the following interventions were applied:

\subsection{Interventions}

\subsubsection{Group A}

Patients received $5 \%$ permethrin cream $30 \mathrm{~g}$ and they were advised to apply the cream to the whole body covering from below neck to toe and it was made to remain in contact with the skin for at least 8 hours. The participants were advised to take scrub bath with warm water before application and on subsequent morning. A second application of same treatment was advised after 7 days.

\subsubsection{Group B}

Patients received $25 \%$ benzyl benzoate lotion and they were advised to apply the lotion to the whole body covering from below neck to toe and it was made to remain contact with the skin for at least 8 hours. The participants were advised to take scrub bath with warm water before application and on subsequent morning. This was done for three consecutive nights.

\subsubsection{Group $C$}

Patients received oral ivermectin in a single dose of $200 \mathrm{mcg} / \mathrm{kg}$ body weight taken with meals and it was repeated after 10 days.

Patients were advised not to use any other medication including anti pruritic agents during the study period.

Participants were advised about treatment of the family members and their close contacts at the same time during the first visit. They were also be advised regarding prevention of fomite transmission by washing all infested clothes and bedding and drying them in the sun.

\subsection{Clinical assessment}

All patients were followed up at the end of first, second and third week to assess the compliance and to evaluate the efficacy and safety of treatment.

At each of the three visits detailed examination of the entire body surface was performed and compared with baseline clinical grading score and itching grading score.

\subsection{A patient was considered as cured if: ${ }^{6}$}

1. No new clinical lesions like papules, vesicles and classical burrows suggestive of live parasite were seen.

2. Patient having improvement in pruritus.

3. Negative parasitological examination at the end of third week.

\subsection{At each visit, improvement was graded as: ${ }^{7}$}

Mild: clinical grading score (grade 2 or 3 ) + itching grading score (grade 2 or 3 ).

Moderate: clinical grading score (grade 1) + itching grading score (grade 1).

Good: clinical grading score (grade 0) + itching grading score (grade 0 ).

The participants who were not cured at the end of three weeks were switched over to treatment with standard $5 \%$ permethrin cream.

The patients were asked for any adverse events occurring during the period of study which was recorded in detail during each follow up visits.

\subsection{Cost effectiveness assessment}

The cost effectiveness was calculated on basis of total expenditure on medicine (in INR) at the end of the third week and cure rate (in \%) and the three groups were compared on the basis of amount needed to treat one case successfully. ${ }^{1}$

- Cost of permethrin 5\% 30g- Rs. 54.75.

- Cost of ivermectin 12mg- Rs. 23 and 6mg- Rs. 16. 
- Cost of benzyl benzoate 25\% 100ml-Rs. 20.

\section{Summary}

1. In this present study, majority of patients (33.3\%) were in age group 21-30 years in group $\mathrm{A}$ and in age group 11-20 years in both group B and group C.

2. Overall, male preponderance was seen with male: female ratio being 1.43:1 and mean age of the patients was $23.7111 \pm 2.276$ years.

3. Majority of patients (46.7\%) in the study group belonged to lower middle class according to B.G Prasad's classification of socioeconomic status.

4. Nocturnal pruritus was seen in $28(93.3 \%)$ patients in group A, 22(73.3\%) patients in group B and 24(80\%) patients in group C.

5. Family history of pruritus was present in $24(80 \%)$ patients in group A, 24(80\%) patients in group B and $26(86.7 \%)$ patients in group C.

6. At baseline, 10 (33.3\%) patients in group A, 9 (30\%) patients in group B and $19(63.3 \%)$ patients in group C had grade 2 pruritus. $14(46.7 \%)$ patients in group A, $17(56.7 \%)$ patients in group B and $7(23.3 \%)$ patients in group $\mathrm{C}$ had grade 3 pruritus.

7. At baseline, $19(63.30 \%)$ patients in group A, 17 $(56.7 \%)$ patients in group B and $13(43.3 \%)$ patients in group $\mathrm{C}$ had clinical grade 2. $6(20 \%)$ patients in group A, $9(30 \%)$ patients in group B and $12(40 \%)$ patients in group $\mathrm{C}$ had clinical grade 3.

8. At the end of third week, decrease in pruritus as assessed by Visual analogue score was maximum in group A with $36 \%$ (11) of patients having grade 0 pruritus as compared to $20 \%$ (6) in group B and $26.7 \%$ (8) in group C. $43.3 \%$ (13) of patients in group A had grade 1 pruritus (mild) compared to $20 \%$ (6) in group $\mathrm{B}$ and $36.7 \%$ (11) in group C.

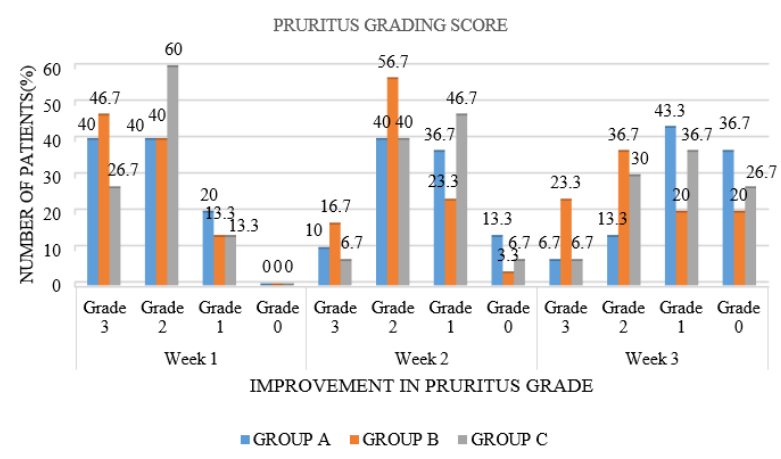

Graph 1: Improvement in pruritus grade at each follow up in the three groups of patients studied.

At the end of third week, assessment of improvement in clinical grade showed that significant number of patients in group A $18(60 \%)$ had clinical grade 0 compared to 11
(36.7\%) patients in group B and $12(40 \%)$ patients in group $\mathrm{C}$ respectively.

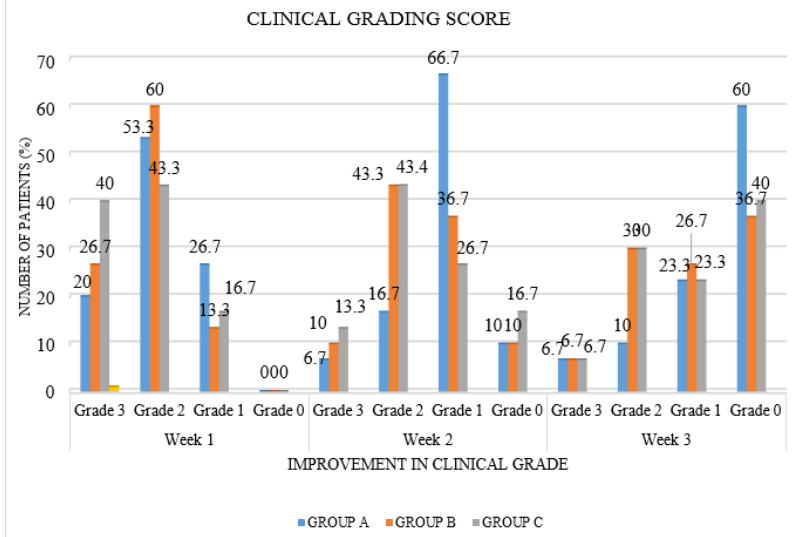

Graph 2: Improvement in clinical grade at each follow up in the three groups of patients studied

1. At the end of third week, complete microscopic clearance was seen in all (100\%) patients in group A, whereas $20(66.7 \%)$ in group B and $24(80 \%)$ in group $\mathrm{C}$ had complete microscopic clearance.

2. At the end of 3 weeks, the mean lesion count in group A patients treated with permethrin cream was less than that of group B patients treated with benzyl benzoate ( $\mathrm{p}=0.818$, which was not statistically significant) and group $C$ patients treated with oral ivermectin $(\mathrm{p}=0.448$ which was not statistically significant).

3. At the end of treatment, group A was having better mean percentage reduction of lesions $(11.2 \%)$ as compared to $7.7 \%$ patients in group $\mathrm{B}(\mathrm{p}=0.818)$ and $9.7 \%$ in group $\mathrm{C}(\mathrm{p}=0.594)$. This was not found to be statistically significant.

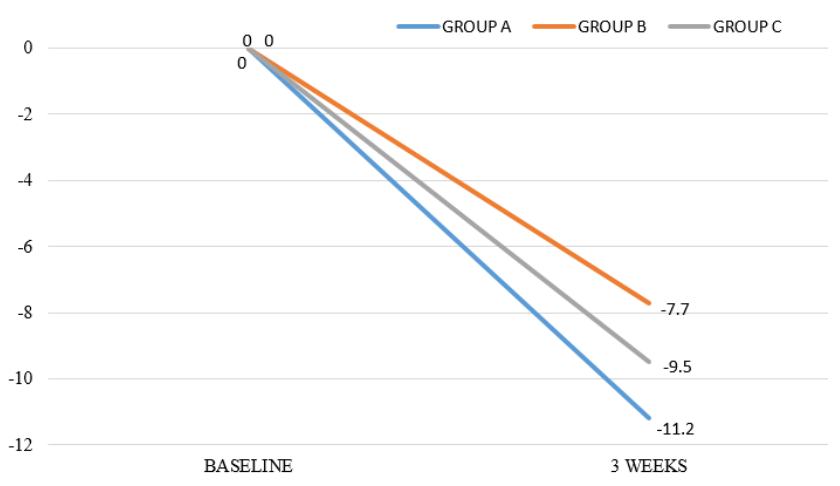

Graph 3: Mean percentage of reduction in lesion count in the three groups of patients studied

1. In the present study at the end of 3 weeks, $36.7 \%$ in group A, $13.3 \%$ in group B and $23.3 \%$ in group C had 
good improvement. Hence, permethrin showed better improvement than benzyl benzoate $(\mathrm{p}=0.0268$ which was significant) and ivermectin ( $\mathrm{p}=0.3175$, which was not found to be significant).

2. At the end of third week, complete clinical cure was seen in $28(93.3 \%)$ patients in group A, $13(43.3 \%)$ patients in group B and 22 (73.3\%) patients in group C. Hence permethrin was more efficacious than benzyl benzoate $(\mathrm{p}=0.00003$ which was highly significant) and ivermectin ( $\mathrm{p}=0.037$ which was significant). Ivermectin was more efficacious than benzyl benzoate ( $\mathrm{p}=0.018$ which was significant).

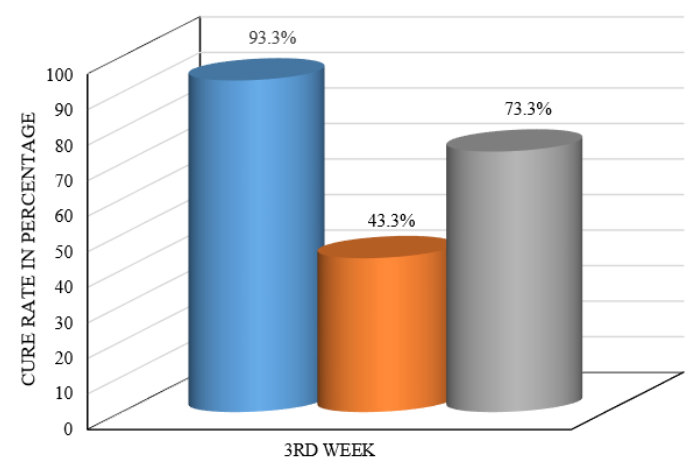

$\because$ GROUP A $=$ GROUP B
= GROUP C

Graph 4: Comparison of complete clinical cure in the three groups of patients at the end of three weeks

1. At the end of treatment at 3 weeks, benzyl benzoate was more cost effective than permethrin ( $\mathrm{p}$ value $<0.00001)$ and ivermectin. ( $\mathrm{p}$ value $<0.00001$ ) which was highly significant.

2. No adverse effects were observed in any of the treatment groups.

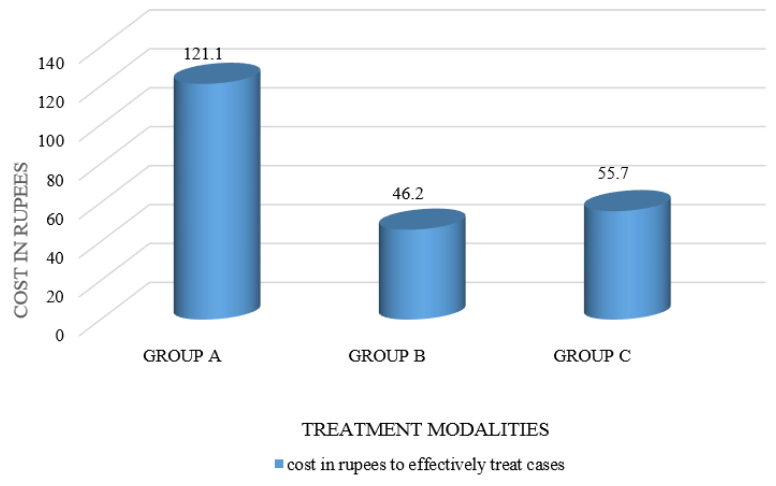

Graph 5: Cost in rupees to effectively cure cases in the three groups of patients studied

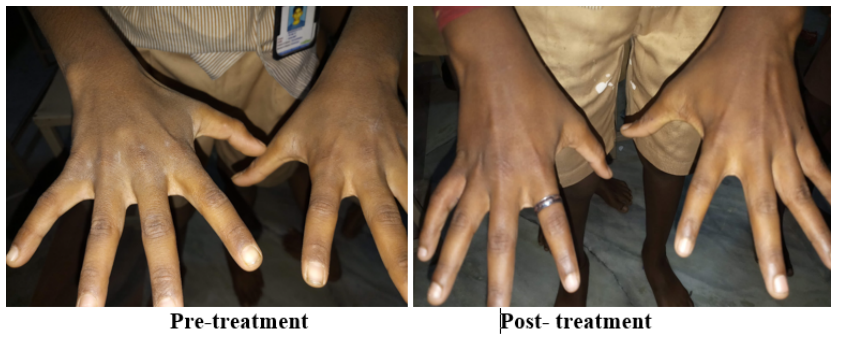

Fig. 1: Group A- patient treated with topical permethrin

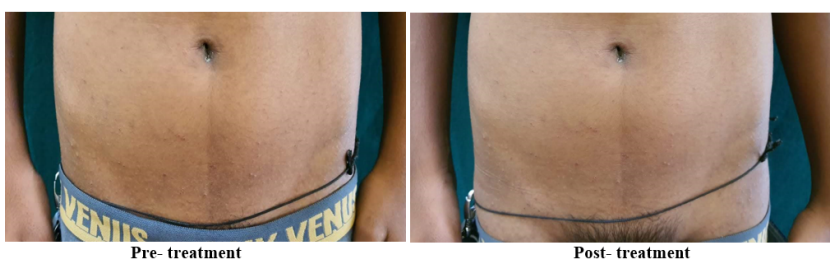

Fig. 2: Group B- patient treated with topical benzyl benzoate lotion
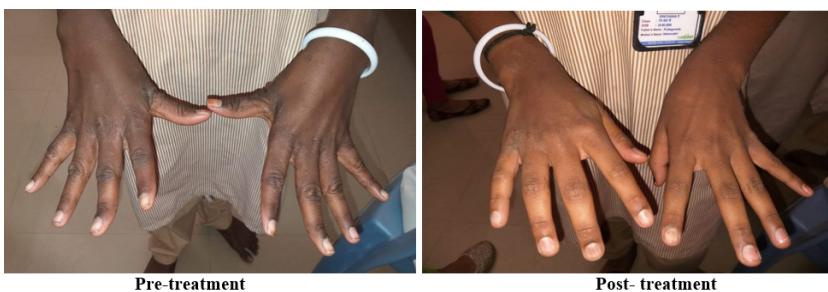

Fig. 3: Group C patient treated with oral ivermectin

\section{Discussion}

\subsection{Introduction}

Scabies is a common public health problem that affects humans regardless of age, gender and social class.

The economical and psycho-social impact of this commonly prevalent disease is significant especially among the population who have poor affordability for the most efficacious anti-scabietic drug, hence we conducted the present study to compare the therapeutic efficacy and cost effectiveness of topical 5\% permethrin, benzyl benzoate $25 \%$ and oral ivermectin in patients with scabies at rural tertiary care hospital.

\subsection{Baseline parameters}

1. In the present study, mean age was found to be 23.7111 \pm 2.276 . In a study conducted by Abdel-Raheem TA et $\mathrm{al},{ }^{3}$ mean age was found to be $25.33 \pm 12.84$ years.

2. In our study, age range was found to be from 6 years to 57 years. In a study conducted by Abdel-Raheem et $\mathrm{al}^{3}{ }^{3}$ age range was found to be between 7 years to 50 years.

3. In the present study, overall male preponderance was seen with male is to female ratio being 1.43:1. In 
another study conducted by Sharma et al, ${ }^{5}$ overall male preponderance was seen with male is to female ratio being 1.5:1. In a study conducted by Abdel-Raheem et $\mathrm{al},{ }^{3}$ overall female preponderance was seen with male to female ratio being $0.72: 1$.

\subsection{Improvement in clinical grading at each follow up}

1. Group A- In the present study, 30 patients were treated with permethrin $5 \%$ cream which was applied to the whole body covering from below neck to toe and it remained in contact with the skin for at least 8 hours. At the end of first week, 26.7\% (8) of patients had clinical grade 1 (mild) and at the end of third week, $60 \%$ (18) of patients in group A had clinical grade 0 . Meenakshi $\mathrm{M}$ et $\mathrm{al}^{7}$ observed that at the end of first week, $32 \%$ of patients had clinical grade 1 , and $4 \%$ of patients treated with permethrin had complete clearance. At the end of three weeks, $52 \%$ of patients treated with permethrin had complete lesion clearance.

2. Group B- In the present study, 30 patients were treated with $25 \%$ benzyl benzoate lotion, which was applied to the whole body covering from below neck to toe and it remained in contact with the skin for at least 8 hours. This was done for three consecutive nights. At the end of first week, $13.3 \%$ (4) patients had clinical grade 1 (mild) and at the end of third week, $36.7 \%$ (11) of patients in group $B$ had clinical grade 0 . With respect to this clinical parameter, there were no similar studies to compare with our observation.

3. Group C-In the present study, 30 patients were treated with oral ivermectin in a single dose of $200 \mathrm{mcg} / \mathrm{kg}$ body weight which was repeated after 10 days At the end of first week, $16.7 \%$ (5) of patients had clinical grade 1 (mild) and at the end of third week, $40 \%$ (12) patients in group $\mathrm{C}$ had clinical grade 0 . Meenakshi $\mathrm{M}$ et $\mathrm{al}^{7}$ observed that at the end of first week, $33 \%$ of patients had clinical grade 1 and $5 \%$ of patients treated with ivermectin had complete clearance. At the end of three weeks, $63 \%$ of patients had complete lesion clearance.

\subsection{Improvement in pruritus at the end of treatment in 3 treatment groups}

1. Group A- In the present study, at the end of three weeks, significant number of patients in group A (43.3\% or 13 ) had mild pruritus, and $36 \%$ (11) had no symptoms of pruritus. In a study done by Meenakshi $\mathrm{M}$ et al, ${ }^{7} 33 \%$ of patients treated with permethrin had mild pruritus and $27 \%$ had no symptoms of pruritus at the end of 3 weeks. In another study done by AbdelRaheem TA et al ${ }^{3} 12 \%$ of patients on permethrin cream had pruritus at the end of 2 weeks, but it was not graded.
2. Group B- In the present study, at the end of three weeks, $20 \%$ (6) of patients in group B had mild pruritus, and $20 \%$ (6) had no symptoms of pruritus. In a study done by Abdel-Raheem TA et al, ${ }^{3} 80 \%$ patients treated with benzyl benzoate had pruritus at the end of second week, but it was not graded.

3. Group C- In the present study, at the end of three weeks, 36.7\% (11) of patients in group $\mathrm{C}$ had mild pruritus, and $26.7 \%$ (8) had no symptoms of pruritus. In a study done by Meenakshi M et al, ${ }^{7} 49 \%$ of patients treated with oral ivermectin had mild pruritus, and 25\% had no symptoms of pruritus. In another study done by Abdel- Raheem TA et al, ${ }^{3} 12 \%$ of patients on oral ivermectin had pruritus at the end of 2 weeks, but it was not graded.

\subsection{Improvement in microscopic clearance in 3 groups}

1. Group A - Complete microbiological clearance was seen in all patients in group A. Similarly, in a study done by Sharma $\mathrm{R}$ et al, ${ }^{5}$ all patients treated with permethrin had complete microscopic clearance. In a study done by Adel-Raheem TA et al, ${ }^{3} 12 \%$ (6) of patients treated with permethrin had a positive microscopic examination after 2 weeks.

2. Group B- In the present study 33.3\% (10) of patients in group B had positive microscopy after 3 weeks. In a study done by Adel-Raheem TA et al, ${ }^{3} 20 \%$ (10) of patients treated with benzyl benzoate had a positive microscopic examination after 2 weeks.

3. Group C- In the present study, $20 \%$ (6) patients in group $\mathrm{C}$ had positive microscopy after 3 weeks. In a study done by Sharma R et al, ${ }^{5} 5.1 \%$ (2) patients treated with single dose of ivermectin $200 \mathrm{mcg} / \mathrm{kg}$ showed positive microscopy at the end of 2 weeks. In a study done by Adel-Raheem TA et al, ${ }^{3}$ 16\% (8) of patients treated with oral ivermectin had a positive microscopic examination after 2 weeks.

\subsection{Cure rate at the end of 3 weeks}

1. Cure rate of Permethrin cream: In the present study at the end of three weeks, $93.3 \%$ (28) of patients treated with permethrin cream had complete clinical cure. Das et $\mathrm{al}^{8}$ found $90 \%$ improvement at the end of the $4^{\text {th }}$ week. Meenakshi M et al ${ }^{7}$ found $93.5 \%$ cure rate at the end of $4^{\text {th }}$ week. Prabodh et al ${ }^{1}$ found $90 \%$ cure rate at the end of $4^{\text {th }}$ week. Abdel-Raheem TA et al ${ }^{3}$ found $88 \%$ cure rate at the end of two weeks.

2. Cure rate of Benzyl Benzoate: In the present study at the end of three weeks, $43.3 \%$ (13) of patients treated with benzyl benzoate lotion had complete clinical cure. Abdel-Raheem TA et al $^{3}$ found $80 \%$ cure rate at the end of two weeks. 
3. Cure rate of Ivermectin: In the present study at the end of three weeks, $73.3 \%$ (22) of patients treated with oral ivermectin had complete clinical cure. Bachewar NP et al ${ }^{9}$ found $100 \%$ cure rate at the end of $4^{\text {th }}$ week. Meenakshi $\mathrm{M}$ et $\mathrm{al}^{7}$ found $98 \%$ cure rate after the $3^{\text {rd }}$ week. Prabodh et al ${ }^{1}$ found $78 \%$ cure rate at the end of $4^{\text {th }}$ week. Abdel-Raheem TA et $\mathrm{al}^{3}$ found $84 \%$ cure rate at the end of two weeks.

4. Comparison of cure rate in three treatment groups: In the present study at the end of third week, complete clinical cure was seen in $28(93.3 \%)$ patients in group A, $13(43.3 \%)$ patients in group B and $22(73.3 \%)$ of patients in group C. Permethrin was more efficacious than benzyl benzoate and ivermectin, which was found to be statistically significant $(\mathrm{p}$ value $=0.00003,0.037$ respectively).

5. In a study done by Abdel-Raheem TA et al, ${ }^{3}$ at the end of two weeks, complete clinical cure was seen in $88 \%$ of patients treated with permethrin, $80 \%$ of patients treated with benzyl benzoate and $84 \%$ of patients treated with oral ivermectin.

\subsection{Cost effectiveness of three groups at the end of treatment}

In the present study when cost effectiveness of the three groups was compared at the end of treatment, benzyl benzoate ( $R s$ 46.20) was found to be more cost effective than permethrin (Rs 121.10) ( $\mathrm{p}$ value<0.00001), and ivermectin (Rs 55.70). Bachewar NP et al $^{9}$ found that permethrin gave faster symptomatic relief but ivermectin was more cost effective. Similarly, Prabodh et al ${ }^{1}$ found that ivermectin was more cost effective than permethrin. AbdelRaheem TA et $\mathrm{al}^{3}$ found that benzyl benzoate was more cost effective than ivermectin. Meenakshi $\mathrm{M}$ et $\mathrm{al}^{7}$ found that ivermectin is more cost effective than permethrin and gamma benzene hexachloride. Chhaiya SB et al ${ }^{10}$ found that ivermectin is more cost effective than permethrin.

\section{Conclusion}

From this study it can be concluded that topical permethrin is the most efficacious in the treatment of scabies, compared to oral ivermectin and topical benzyl benzoate.

However, topical benzyl benzoate was more cost effective than topical permethrin and oral ivermectin.

\section{Source of Funding}

No financial support was received for the work within this manuscript.

\section{Conflict of Interest}

The authors declare that they have no conflict of interest.

\section{References}

1. Prabodh W, Vikas D. Acomparative Study of Topical Permethrin, Oral Ivermectin and Combination of Permethrin with Ivermectin In Patients Of Scabies. IOSR J Dent Med Sci. 2016;15(5):67-72.

2. Mila-Kierzenkowska C, Woźniak A, zyńska EK. Comparative Efficacy of Topical Pertmehrin, Crotamiton and Sulfur Ointment in Treatment of Scabies. J Arthropod-Borne Dis. 2017;11:1-9.

3. Abdel-Raheem TA, Méabed EMH, Nasef GA, Wahed WYA, Rohaim RMA. Efficacy, acceptability and cost effectiveness of four therapeutic agents for treatment of scabies. J Dermatol Treat. 2016;27(5):473-9.

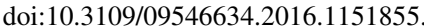

4. Beeres DT, Ravensbergen SJ, Heidema A, Cornish D, Vonk M, Wijnholds LD. Efficacy of ivermectin mass-drug administration to control scabies in asylum seekers in the Netherlands : A retrospective cohort study between; 2014.

5. Singal A, Sharma R. Topical permethrin and oral ivermectin in the management of scabies: A prospective, randomized, double blind, controlled study. Indian J Dermatol, Venereol, Leprol. 2011;77(5):581-6. 001:0.4103/03/8-6323.84063.

6. Hoffmann JC, Mößner R, Schön MP, Lippert U. Topical scabies therapy with permethrin is effective and well tolerated in infants younger than two months. JDDG: J der Deutschen Dermatologischen Gesellschaft. 2019;17(6):597-600. doi:10.111/ddg.13854.

7. Meenakshi M, Sadhna K, Neeraj S, Deepak V, Renu P. An open label, randomized, comparative study of anti-scabietic drugs permethrin, gamma benzene hexachloride and ivermectin in patients of uncomplicated scabies. Int J Pharmacol Clin Sci. 2014;3:15-21.

8. Das S, Chatterjee T, Banerji G, Biswas I. Evaluation of the commonest site, demographic profile and most effective therapy in scabies. Indian J Dermatol. 2006;51(3):186-8. 10:-10.4103/0019-5/54.27981].

9. Thawani VR, Mali SN, Gharpure KJ, Shingade VP, Dakhale GN, Bachewar NP, et al. Comparison of safety, efficacy, and cost effectiveness of benzyl benzoate, permethrin, and ivermectin in patients of scabies. Indian J Pharmacol. 2009;41(1):9-14. 101:10.4Tण3/0253-76/3.48882

10. Chhaiya S, Patel V, Dave J, Mehta D. To study cost effectiveness of topical permethrin versus oral ivermectin in patients of uncomplicated scabies. Int J Basic Clin Pharmacol. 2017;2(6):799-803.

\section{Author biography}

Rashmi R Mallya, Junior Resident

Ranga Swaroop, Professor and HOD

K Yashwanth Reddy, Junior Resident

Avik Ghosh, Senior Resident

Zigu S Krishn, Junior Resident

Cite this article: Mallya RR, Swaroop R, Reddy KY, Ghosh A, Krishn ZS. Study of efficacy and cost effectiveness of topical permethrin, benzyl benzoate and oral ivermectin in the treatment of scabies. $I P$ Indian J Clin Exp Dermatol 2021;7(1):54-60. 